Original Research Paper

\title{
Gelatin Extraction of Alaska Pollock (Theragra chalcogramma) Dry Skin
}

\author{
${ }^{1}$ Yanan Li, ${ }^{1}$ Fangyuan Chen, ${ }^{1}$ Jiong Zou, ${ }^{2}$ Mingyu Zhi and ${ }^{1,3}$ Guangrong Huang \\ ${ }^{I}$ College of Life Sciences, China Jiliang University, Hangzhou, China \\ ${ }^{2}$ Hangzhou Vocational and Technical College, Hangzhou, China \\ ${ }^{3}$ Key Lab of Marine Food Quality and Hazard Controlling Technology of Zhejiang Province, Hangzhou, China
}

Article history

Received: 19-11-2017

Revised: $10-01-2018$

Accepted: 26-01-2018

Corresponding Author: Guangrong Huang

College of Life Sciences, China Jiliang University, Hangzhou,

China

Email: grhuang@126.com

\begin{abstract}
Alaska Pollock is rich in resource. And during its processing, skin is peeled as byproducts. The skin of Alaska Pollock contains lots of collagen or gelatin, promising materials, which can be used in food, cosmetics, biomedical and pharmaceutical industries. Extracting collagen from the dry skin of Alaska Pollock is studied in this study to provide a better basement for fully using this renewable resource. Three kinds of gelatin were extracted by using acid, pepsin-assisted acid and hot water, respectively. The productivity of Acid Soluble Gelatin (ASG), Pepsin Soluble Gelatin (PSG) and hot Water Soluble Gelatin (WSG) were 7.33, 30.89 and $12.67 \%$, respectively. Their UV absorption spectrum were similar and match with the absorption of dilute protein solution. The protein contents of ASG, PSG and WSG were 84-90\%, with no significantly difference between them. The characters of SDS-PAGE and the circular dichroism spectrum shown that the PSG is broken into small fragment and has less secondary structure. In conclusion, the hot water extraction is the best way to extract the gelatin from the dry skin of Alaska Pollock.
\end{abstract}

Keywords: Alaska Pollock, Fish Skin, Fish Byproduct, Gelatin, SDSPAGE, Circular Dichroism Spectrum

\section{Introduction}

Alaska Pollock (Theragra chalcogramma) is the world's second most important fish species in terms of total catch (FAO, 2010). Alaska Pollock distributed in the North Pacific and have the largest concentrations in the eastern Bering Sea (AFSC, 2016). The Alaska Pollock has been said to be "the largest remaining source of palatable fish in the world" (Barowitz, 2009). Alaska Pollock is widely consumed in USA, Korean and so on.

During the processing of Alaska Pollock, skin are often peeled. These byproducts are discarded or used to produce low value feed (Guo et al., 2013). These skin is rich of gelatin. While collagen, gelatin and collagen peptide have been used in food, cosmetics, biomedical and pharmaceutical industries (Le et al., 2014). Extracting gelatin from the skin of Alaska Pollock improves the added value of low value byproduct, skin. Besides, as renewable biomaterials, gelatin is an important sustainable and harmless resource. The usage of collagen or gelatin is a good way to release the earth pressure. We need more and more resources as our population growth and society development. Alaska
Pollock has huge biomass which is still not fully developed by us as the other marine product. So it is meaningful to study the gelatin isolated from the marine material, such as Alaska Pollock. What's more, compared with land-based animal gelatin, Alaska Pollock derived gelatin has no worry about the epidemic disease of this livestock (Le et al., 2014) and the religion problems from Sikhs, Hindus, Muslims and Jews (Veeruraj et al., 2013).

There are lots of researches studying the extraction and character of collagen from Alaska Pollock fresh skin (Guo et al., 2015; Yang et al., 2012; Zhou et al., 2006; 2005). The extraction methods include the hot water extraction (Guo et al., 2013; Zhou et al., 2004), acid extraction (Yan et al., 2008) and the enzymes assistant extraction (Yang et al., 2012). However all the experiments above used the fresh skin, dry skin of Alaska Pollock (Myungtae) is also produced during the process of drying Alaska Pollack (Cho et al., 2008). Although dry skin derived gelatin has no collagen activities. We won't need non-denature collagen or just need gelatin most time. Besides, the denatured collagen or gelatin can be hydrolyzed to collagen peptide as food 
supplements and so on. On the other way, dry skin of Alaska Pollock has its advantages on the storage, transport and process compared with the fresh materials. Then we chose the dry Alaska Pollock skin as our object. We extract the gelatin from the dry skin of Alaska Pollock in three ways and test some characterizations of them.

\section{Materials and Methods}

\section{Chemicals}

Acetic acid, sodium chloride, pepsin (from pig, 3000 $\mathrm{U} / \mathrm{mg}$, Macklin), isopropanol alcohol, sodium hydroxygen, dialysis bag (cutoff $3500 \mathrm{Da}$ ), potassium sodium tartrate, copper sulfate pentahydrate, Sodium Dodecyl Sulfate (SDS), acrylamide, ammonium persulfate, N,N,N,Ntetramethyl ethylene diamine (TEMED), tris and the real band 3-color high range protein makers were purchased from Sangon Biotec (Shanghai, China) Co. Ltd. The other chemicals and reagents were of analytical grade or electrophoresis grade.

\section{Collection of Fish Skin Sample}

The dry skin of Alaska Pollock were purchased from Yanbian Korean autonomous prefecture (Lat.42 29 N, long. $129^{\circ} 56$ E), Jilin, China. The dry fish skin were removed the remaining meat and scales, washed with distilled water and dry again at $20-2^{\circ} \mathrm{C}$. Then the fish skin was cut to small pieces, sealed and stored at $-20^{\circ} \mathrm{C}$ until further used.

\section{Proximate Composition}

The proximate composition of dry Alaska Pollock skin was determined. The amount of ash, moisture, fat and nitrogen were determined according to the AOAC (Hoorwitz et al., 2012) methods.

\section{Isolation and Purification of Collagen}

All the experiments were performed at $4^{\circ} \mathrm{C}$ unless otherwise indicated.

\section{Pretreatment of Outer Skin Waste}

Fat, non-collagenous proteins and minerals were removed from the dry skin of Alaska Pollock according to procedures described (Pal and Suresh, 2017) with modification. Briefly, the small pieces of dry skin was defatted with isopropanol alcohol (1:30 weights per volume) for $6 \mathrm{~h}$ and then washed with distilled water. After this, the skin was treated with $0.5 \%(w / v) \mathrm{NaOH}$ (1:20 weights per volume) for $0.5 \mathrm{~h}$ to remove noncollagenous proteins and pigment, washed with distilled water to the neutral $\mathrm{pH}$. At last the treated fish skin was lyophilized and stored at $-20^{\circ} \mathrm{C}$ to be further used.

\section{Extraction of Gelatin}

The lyophilized Alaska Pollock skin was soaked in three kind of solutions (1:25, weights: volume) for some time to extract gelatin as the method of Nagai et al. (2004) and method of Tylingo et al. (2016) with slight modification. The solutions and time were $0.5 \mathrm{M}$ acetic acid for 2 days, $0.5 \mathrm{M}$ acetic acid contain pepsin $(30 \mathrm{kU}$ per g dry skin) for 2 days and $70^{\circ} \mathrm{C}$ distilled water for 6 $\mathrm{h}$, the production were Acid Soluble Gelatin (ASG), Pepsin Soluble Gelatin (PSG) and hot Water Soluble Gelatin (WSG) accordingly. Then the extracts were centrifuged at $10000 \times \mathrm{g}$ for $10 \mathrm{~min}$ and collect the supernatant as gelatin solutions.

The purification was prepared by the method of Krishnamoorthi et al. (2017) with slight modification. The supernatant was desalted out by adding $\mathrm{NaCl}$. The ASG and PSG were re-dissolved in $0.5 \mathrm{M}$ acetic acid and dialyzed against $0.1 \mathrm{M}$ acetic acid for 1 day, distilled water for 2 days until the neutral $\mathrm{pH}$ was obtained by dialysis bag. The WSG were re-dissolved in distilled water and dialyzed against distilled water for 3 days. Then the dialyzates were lyophilized and stored at $-20^{\circ} \mathrm{C}$.

\section{Productivity and Characterization}

\section{Productivity}

The lyophilized products of three methods were weighed accurately. Then the yield was weight of dry fish skin divided weight of freeze-dried gelatin.

\section{UV Absorption Spectrum}

UV absorption spectrum of three kinds of gelatin were measured using a UV-VIS Spectrophotometer (Shimadzu, Japan). The gelatin were dissolved in distilled water at final concentration of $0.1 \mathrm{mg} / \mathrm{ml}$. The UV spectrum was measured at such parameters: wavelength between 185 and $400 \mathrm{~nm}$, scan speed of $2 \mathrm{~nm} / \mathrm{s}$ and interval of $1 \mathrm{~nm}$. And the spectrum were used identified its protein compare with the other collagen UV spectrum.

\section{Determination of Protein Content}

The protein content of isolated gelatin was determined by the modification of micro-Biuret method (Itzhaki et al., 1964) with bovine serum albumin as a standard protein. Formulated $10 \mathrm{mg} / \mathrm{ml}$ standard protein solution by bovine serum albumin. A $1.0 \mathrm{ml}$ of standard protein solution or sample mixed with $4.0 \mathrm{ml}$ of biuret reagent. The solution was placed for $30 \mathrm{~min}$ under room temperature $25^{\circ} \mathrm{C}$. At last the absorbance was measured at $540 \mathrm{~nm}$. According the results, find the relationship between the concentration of protein and the absorbance. And then found the concentration of the sample. The purity was weight of extraction divided protein content.

\section{SDS-PAGE}

Sodium Dodecyl Sulfate-Polyacrylamide Gel Electrophoresis (SDS-PAGE) was performed according to the method of Laemmli (1970) with slight modifications. Gelatin samples were dissolved in 
distilled water at a concentration of $5 \mathrm{mg} / \mathrm{ml}$ and then mixed with sample buffer at a gelatin/sample buffer ratio of $4: 1(\mathrm{v} / \mathrm{v})$. The buffer was consisted of $0.6 \mathrm{ml} 1.0 \mathrm{M}$ Tris- $\mathrm{HCl}(\mathrm{pH} 6.8), 5.0 \mathrm{ml} \mathrm{50 \%}$ glycerol, $2.0 \mathrm{ml} \mathrm{10 \%}$

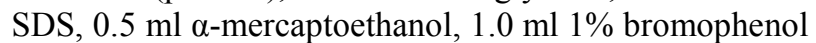
blue, $0.9 \mathrm{ml}$ distilled water. The mixture was heated at $100^{\circ} \mathrm{C}$ for $10 \mathrm{~min}$ and then centrifuged $(10000 \times \mathrm{g}, 10$ min). The supernatant was loaded onto the acrylamide gel. Parameter was 5\% acrylamide gel as stacking gel and $10 \%$ acrylamide gel as separating gel. Voltage values of enrichment and separation were $80 \mathrm{~V}$ and 120 $\mathrm{V}$ correspondently. The realband 3-color high range protein makers were used to estimate the molecular weight of proteins. After electrophoresis, the gel was stained by using staining solution containing the methanol: acetic acid: water: Coomassie brilliant blue R250 (450:100:450:1). Then the gels were destained with methanol, acetic acid and water $(1: 1: 8)$. At last, the gels were photo.

\section{Circular Dichroism (CD) Measurement}

Extracted gelatin was dissolved in distilled water in the concentration of $0.1 \mathrm{mg} / \mathrm{ml}$. The CD spectra measurements were performed by circular dichroism spectrometer (JASCO J-815, Japan) with the parameters: wavelengths $350-185 \mathrm{~nm}$, scanning speed $200 \mathrm{~nm} / \mathrm{min}$, data pitch $1 \mathrm{~nm}$ and band width $5.00 \mathrm{~nm}$.

\section{Statistical Analyses}

All the experiments were replicated three times. The data were analyzed by the SPSS 19.

\section{Results and Discussion}

\section{Proximate Composition}

Dry skin of Alaska Pollock contained 4.88 $\pm 0.69 \%$ ash, $7.03 \% \pm 0.20 \%$ water, $1.29 \% \pm 0.23 \%$ lipid, $85.46 \% \pm 1.05 \%$ protein. The compositions of Alaska Pollock dry skin were similar to those of frog (Rana nigromaculata) skin (Zhang and Duan, 2017), forest frog (Rana chensinensis) (Jing et al., 2016) and the fresh Alaska Pollock skin (Chan et al., 2007) by dry materials. This result also further proved that the skin consistent of aquatic animal were similar.

Dry skin of Alaska Pollock was consisted by protein, water, lipid and the minerals and its major component is protein. While the major protein of fish skin is collagen. So the dry skin of Alaska Pollock is a good source of collagen.

\section{Yield and Protein Content of ASG, PSG and WSG}

The yield of ASG, WSG and PSG were 7.33, 30.89 and $12.67 \%$, shown in Table 1 . The yield of WSG were highest, followed by PSG, ASG. The yield of ASG was highly significantly different from WSG and PSG. The yield of PSG were similar to the alcalase or neutrase assisted extraction collagen from fresh skin of Alaska Pollock (Yang et al., 2012), PSG from frog skin (Zhang and Duan, 2017). However, the yield of WSG from Alaska Pollock was higher than WSG from fresh skin (Zhou et al., 2004; 2005; 2006), which may be caused by the higher extraction temperature and the longer extraction time. Besides, the PSG had a higher productivity than AGS may for the pepsin can help the extraction of gelatin.

Three gelatins had similar UV absorption characters, shown in Fig. 1. At the concentration of $0.1 \mathrm{mg} / \mathrm{ml}$, all these gelatins had no absorption at $280 \mathrm{~nm}$ and strong absorption at $215 \mathrm{~nm}$. This results match with the spectrum characters of dilute protein solution: protein still have strong absorption at $215 \mathrm{~nm}$ at a low concentration. The $215 \mathrm{~nm}$ is the absorption peak of protein peptides (Liyanage et al., 2014) and $280 \mathrm{~nm}$ is the absorption peak of tryptophan, tyrosine and phenylalanine. Besides, it also means all these products contain no other substance with the absorption at wavelength different from $215 \mathrm{~nm}$. This result is also a proof of the purity of the gelatins. Besides, we also found that all these gelatins have absorption at both 280 $\mathrm{nm}$ and $215 \mathrm{~nm}$ in the concentration of $5 \mathrm{mg} / \mathrm{ml}$ just as Veeruraj's research (Veeruraj et al., 2013).

The protein content of ASG, WSG and PSG were $84.22,89.89$ and $90.86 \%$, respectively (Table 1 ). The protein content of ASG, WSG and PSG had no significantly different by ANOVA analysis. The protein content was higher than other literature reported 18.4 and $48.6 \%$ (Krishnamoorthi et al., 2017). And some literature use the gelatin/collagen extracted by these methods as pure collagen/gelatin (Iswariya et al., 2017). The reason may due to the determination method of protein content or species specificity. Most research used the Folin-reagent method of Lowry et al. And this method is sensitivity to the tyrosine, tryptophan and cysteine in the protein (Peterson, 1979). While the collagen is very special for it is less in these amino acids. And the method of Biuret is based on the peptide bond (Goa, 1953) which has no difference between different proteins. So this protein content was higher than other reports. We also got the results of about $60 \%$ by the Folin-reagent method. These results were similar to the $48.6 \%$ of Krishnamoorthi et al. (2017).

\section{Structure Characterization of ASG, WSG and PSG}

Gel electrophoresis pattern of gelatins was shown in Fig. 2. The SDS-PAGE pattern showed that patterns of ASG and WSG are similar. Both ASG and WSG were consisted of three major bands, which were about $100 \mathrm{k} \mathrm{Da}, 200 \mathrm{k} \mathrm{Da}$ and $>254 \mathrm{k} \mathrm{Da}$. The WSG was similar to the pattern of Alaska Pollock skin gelatin (Zhou et al., 2006). 
Yanan Li et al. / American Journal of Biochemistry and Biotechnology 2018, 14 (1): 13.19 DOI: 10.3844/ajbbsp.2018.13.19

Table 1: Yield and protein content of ASG, PSG and WSG*

\begin{tabular}{llll}
\hline Item & ASG & WSG & PSG \\
\hline Yield (\%) & $7.33 \pm 0.33^{\mathrm{Aa} a^{* *}}$ & $30.89 \pm 1.39^{\mathrm{Bb}}$ & $12.67 \pm 0.88^{\mathrm{Cc}}$ \\
Protein content (\%) & $84.22 \pm 0.22^{\mathrm{Aa}}$ & $89.89 \pm 0.22^{\mathrm{Aa}}$ & $90.86 \pm 3.32^{\mathrm{Aa}}$ \\
\hline
\end{tabular}

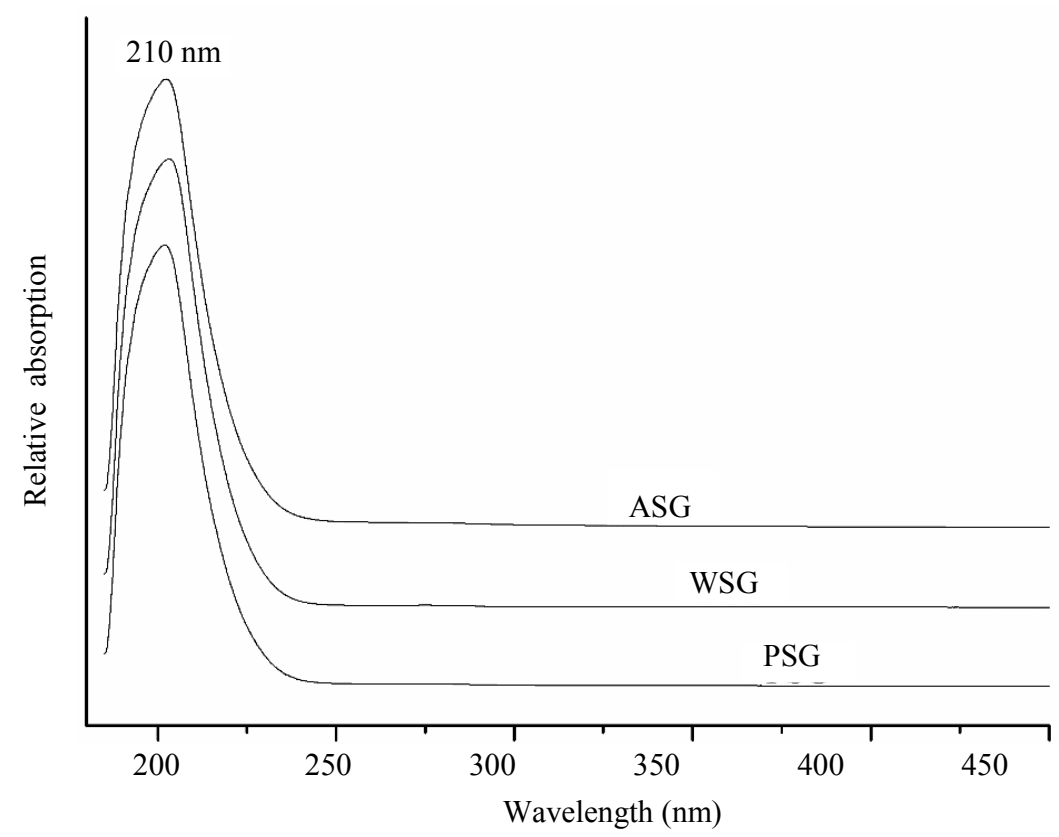

Fig. 1: The UV-Spectrum of Acid Soluble Gelatin (ASG), hot Water Soluble Gelatin (WSG) and Pepsin Soluble Gelatin (PSG)

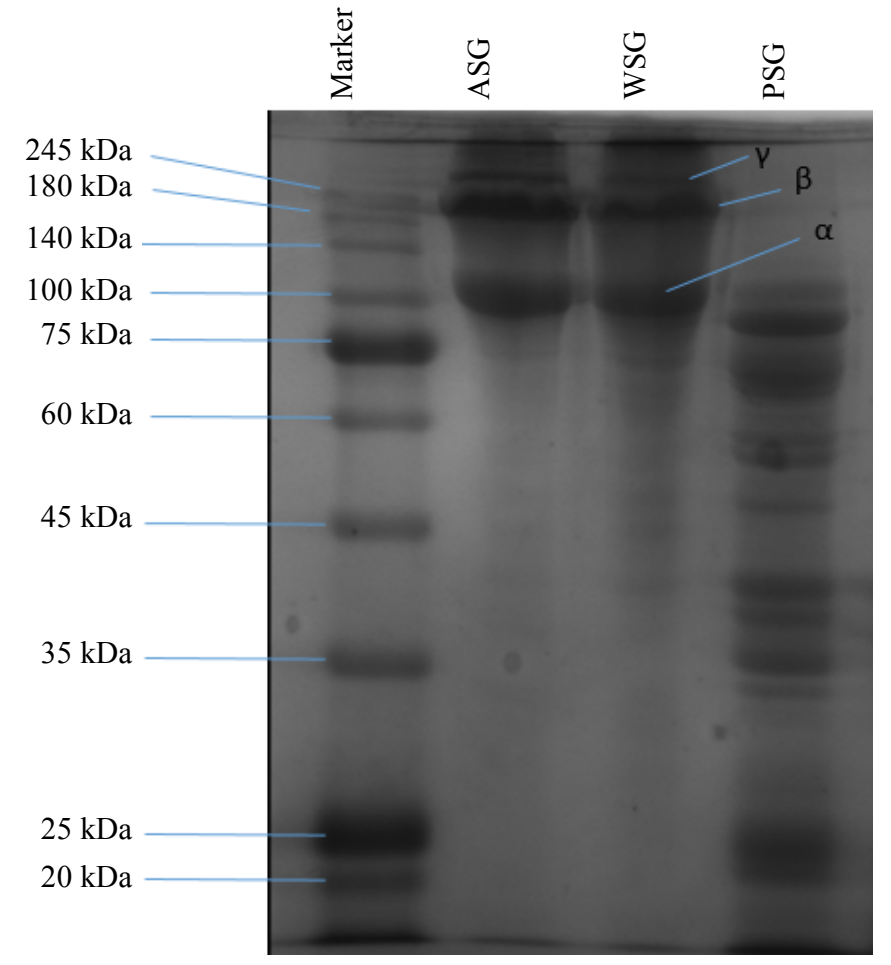

Fig. 2: The SDS-PAGE pattern of gelatins. ASG: Acid solution gelatin; WSG: Hot water soluble gelatin; PSG: Pepsin soluble gelatin. $\alpha, \beta$ and $\gamma$ mean the single peptide chain, dimers and trimers correspondently 
These bands matched with $\alpha$ chain, $\beta$ chain (dimers) and $\gamma$ chain (trimers) of collagen. These results suggested that both ASG and PSG were most likely to be classified as type I collagen. Similarly, SDS-PAGE of Alaska Pollock ASG had one bold bands were identified as type I collagen (Chan et al., 2007). The PSG was different from ASG and WSG with the fragments range from $20 \mathrm{k}$ Da to $100 \mathrm{k} \mathrm{Da}$. The PSG was similar to the peptide mapping of frog skin acid-soluble collagen digested by pepsin at $30^{\circ} \mathrm{C}$ with part of $\alpha$ chain and lots of low molecular fragments (Zhang and Duan, 2017). During the extraction of PSG, gelatin was digested by pepsin and components of ASG were cleaved into small molecular components. In summary, ASG and WSG have complete collagen peptide chain, PSG have been hydrolyzed by pepsin to small fragments.

The Circular Dichroism spectrum (CD) and secondary structure content of ASG and PSG were shown in Fig. 3. Although their CD of three gelatins were similar, their secondary structure content can still be computed by the $\mathrm{CD}$ chromatograph. From the secondary structure content of three gelatins, we found all the three extractions had no $\alpha$-helix. The PSG had no $\beta$-folding, while WSG and ASG still contained 25.9\% and $32.9 \% \beta$-folding correspondingly. The $\beta$-turn content of PSG was relative lower than WSG and ASG. At the same time the PSG had more unordered structure.

All the three extractions having no $\alpha$-helix showed that they did not contain structure of triple helix form. And then they were gelatins. The PSG had no $\beta$-folding and less $\beta$-turn showed that its structure was destroyed massively. At the same time, PSG had more random coil than WSG and PSG. Both of them indicated the pepsin had hydrolyzed the collagen and destroyed the peptide chain. Those phenomenon also matched the results of SDS-PAGE which showed more fragments in the PSG. Iswariya et al. (2017) used the Infrared Spectroscopy (IR) determining the structure of collagen. However the CD spectrum is more convenient and the second structure content is easier to get than IR (Jenness et al., 1976; Sreerama et al., 1999). Ennaas et al. (2016) used the CD spectrum to determine the secondary structure of synthetic collagencin, an antibacterial peptide from fish collagen. And the different secondary structure content of three gelatins also fitted that gelatins having different kinds of hydrolysates level.

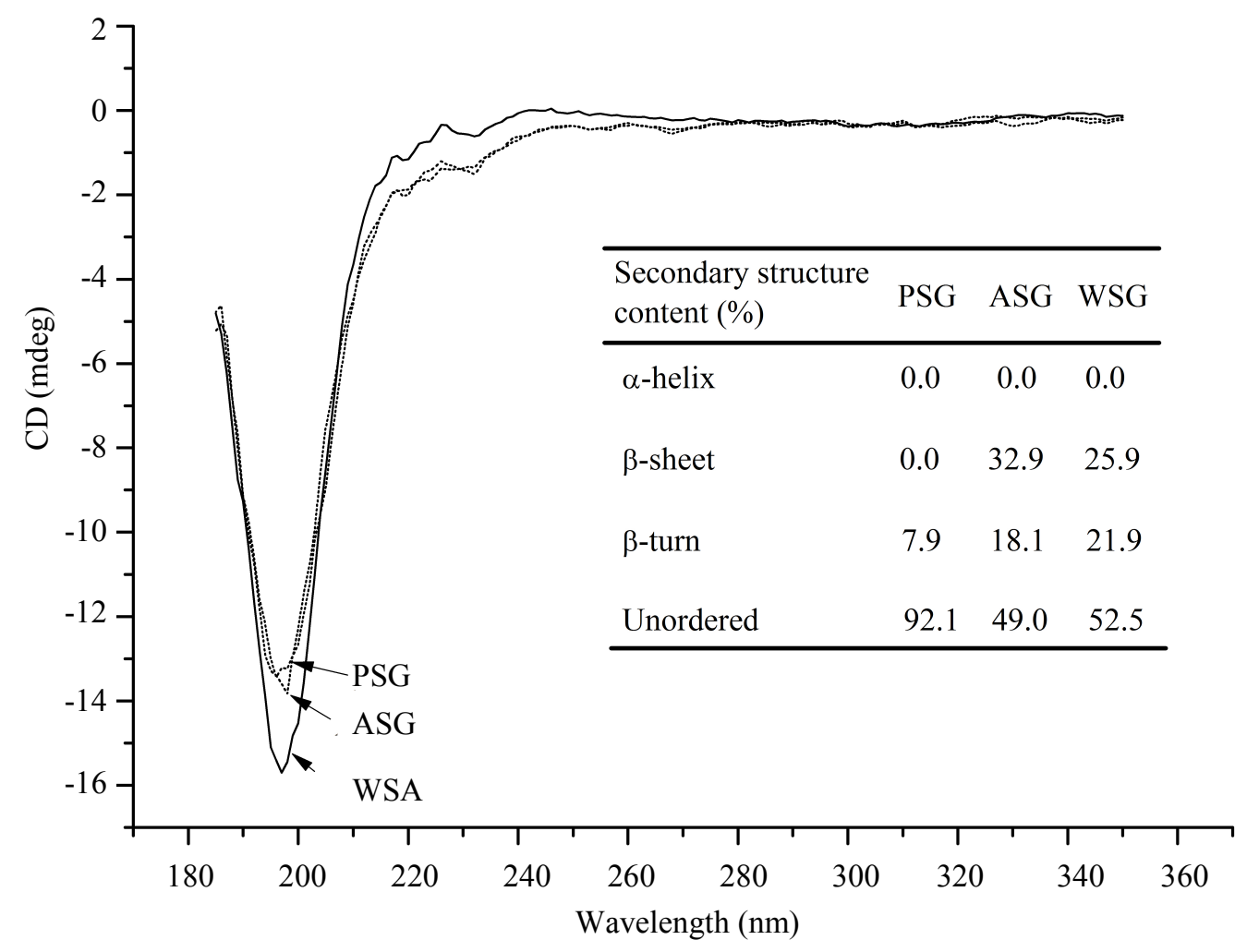

Fig. 3: The CD spectrum and secondary structure content of three gelatins. Acid Solution Gelatin (ASG); Hot Water Soluble Gelatin (WSG); Pepsin Soluble Gelatin (PSG) 


\section{Conclusion}

Hot water extraction collagen from the dry skin of Alaska Pollock is an effect and economic way to get gelatin. The dry skin of Alaska Pollock is rich in protein with a content of $85.46 \%$. What's more the WSG with a yield of $30.89 \%$ and purity of $89.89 \%$. As for the gelatin has huge application in food, cosmetics, biomedical and pharmaceutical industries. The dry skin of Alaska Pollock can be a promising source of gelatin and has huge value. The WSG still maintain the full length of collagen chain, as well as the ASG. Both of them would keep some regular secondary structure. While the PSG is the fragment of collagen and is ordered.

\section{Acknowledgement}

This research is supported by the Science and Technology Project of Zhejiang, Province, China [grant number 2016C32064] and Zhejiang Natural Science Foundation of China [grant number LY18C200001]. The founding sponsor had no role in the design of the study; in the collection, analyses, or interpretation of data; in the writing of the manuscript and in the decision to publish the results.

\section{Author's Contributions}

Yanan Li: Performed the experiments and wrote the manuscript.

Jiong Zou and Fangyuan Chen: Participated in partial experiments.

Mingyu Zhi and Guangrong Huang: Developed the idea and advised in experimental methods.

\section{Ethics}

The authors declare that they had no conflict of interest.

\section{References}

AFSC, 2016. AFSC Walleye pollock research. Alaska Fisheries Sci. Center. https://www.afsc.noaa.gov/species/pollock.php

Barowitz, Z., 2009. The end of the line: How overfishing is changing the world and what we eat. Gastronomica, 9: 110-111.

Chan, H.P., J.H. Lee, K.T. Kang, J.W. Park and J. S. Kim, 2007. Characterization of acid-soluble collagen from Alaska Pollock surimi processing byproducts (refiner discharge). Food Sci. Biotechnol., 16: 549-556. DOI: 10.1007/s10068-010-0004-3

Cho, S.S., H.K. Lee, C.Y. Yu, M.J. Kim and E.S. Seong et al., 2008. Isolation and charaterization of bioactive peptides from Hwangtae (yellowish dried Alaska pollack) protein hydrolysate. J. Food Sci. Nutrit., 13: 196-203. DOI: 10.3746/jfn.2008.13.3.196
Ennaas, N., R. Hammami, A. Gomaa, F. Bédard and É. Biron et al., 2016. Collagencin, an antibacterial peptide from fish collagen: Activity, structure and interaction dynamics with membrane. Biochem. Biophys. Res. Commun., 473: 642-647. DOI: $10.1016 /$ j.bbrc.2016.03.121

FAO, 2010. The state of world fisheries and aquaculture. Rome Italy FAO, 4: 40-41.

Goa, J., 1953. A micro biuret method for protein determination; determination of total protein in cerebrospinal fluid. Scandinavian J. Clin. Laboratory Investigation, 5: 218-222. DOI: $10.3109 / 00365515309094189$

Guo, L., P.A. Harnedy, L. Zhang, B. Li and Z., Zhang et al., 2015. In vitro assessment of the multifunctional bioactive potential of Alaska pollock skin collagen following simulated gastrointestinal digestion. J. Sci. Food Agric., 95: 1514-1520.

DOI: $10.1002 /$ jsfa. 6854

Guo, L., H. Hou, B. Li, Z. Zhang and S. Wang et al., 2013. Preparation, isolation and identification of iron-chelating peptides derived from Alaska pollock skin. Process Biochem., 48: 988-993. DOI: $10.1016 /$ j.procbio.2013.04.013

Hoorwitz, N., P. Chialo, H. Reynolds and K. Helrich, 2012. Official methods of analysis association of official analytical chemists. J. Pharmaceutical Sci., 60: 414-414.

Iswariya, S., P. Velswamy and T.S. Uma, 2017. Isolation and characterization of biocompatible collagen from the skin of Puffer Ffsh (Lagocephalus inermis). J. Polymers Environ. DOI: 10.1007/s10924-017-1107-1

Itzhaki, R.F. and D.M. Gill, 1964. A micro-biuret method for estimating proteins. Anal. Biochem., 9: 401-410. DOI: 10.1016/0003-2697(64)90200-3

Jenness, D.D., C. Sprecher and W.C.J. Jr, 1976. Circular dichroism of collagen, gelatin and poly (proline) II in the vacuum ultraviolet. Biopolymers, 15: 513-521. DOI: 10.1002/bip.1976.360150308

Jing, L.U. M.X. Chen, W.S. Ling, H.U. Si-Zhuo and S. Guan et al., 2016. Optimization of collagen extraction from forest frog dry skin by response surface method (in Chinese). Food Sci. Technol.

Krishnamoorthi, J., P. Ramasamy, V. Shanmugam and A. Shanmugam, 2017. Isolation and partial characterization of collagen from outer skin of Sepia pharaonis (Ehrenberg, 1831) from Puducherry coast. Biochem. Biophys. Reports, 10: 39-45. DOI: $10.1016 /$ j.bbrep.2017.02.006

Laemmli, U.K., 1970. Cleavage of structural proteins during the assembly of the head of Bacteriophage T4. Nature, 227: 680-685. DOI: 10.1038/227680a0

Le, T.M.T., E. Okazaki and K. Osako, 2014. Isolation and characterization of acid-soluble collagen from the scales of marine fishes from Japan and Vietnam. Food Chem., 149: 264-270. DOI: 10.1016/j.foodchem.2013.10.094 
Liyanage, M.R., K. Bakshi, D.B. Volkin and C.R. Middaugh, 2014. Ultraviolet absorption spectroscopy of peptides. Meth. Mol. Biol., 1088: 225-236. DOI: 10.1007/978-1-62703-673-3 15

Nagai, T., M. Izumi and M. Ishii, 2004. Fish scale collagen: Preparation and partial characterization. Int. J. Food Sci. Technol., 39: 239-244. DOI: $10.1111 / \mathrm{j} .1365-2621.2004 .00777 . \mathrm{x}$

Pal, G.K. and P.V. Suresh, 2017. Comparative assessment of physico-chemical characteristics and fibril formation capacity of thermostable carp scales collagen. Mater. Sci. Eng. C, 70: 32-40. DOI: $10.1016 /$ j.msec.2016.08.047

Peterson, G.L., 1979. Review of the Folin phenol protein quantitation method of Lowry, Rosebrough, Farr and Randall. Anal. Biochem., 100: 201-220. DOI: 10.1016/0003-2697(79)90222-7

Sreerama, N., S.Y.U. Venyaminov and R.W. Woody, 1999. Estimation of the number of $\alpha$-helical and $\beta$ strand segments in proteins using circular dichroism spectroscopy. Protein Sci., 8: 370-380. DOI: $10.1110 /$ ps.8.2.370

Tylingo, R., G. Gorczyca, S. Mania, P. Szweda and S. Milewski, 2016. Preparation and characterization of porous scaffolds from chitosan-collagen-gelatin composite. Reactive Functional Polymers, 103: 131-140.

DOI: 10.1016/j.reactfunctpolym.2016.04.008

Veeruraj, A., M. Arumugam and T. Balasubramanian, 2013. Isolation and characterization of thermostable collagen from the marine eel-fish (Evenchelys macrura ). Process Biochem., 48: 1592-1602.

DOI: $10.1016 /$ j.procbio.2013.07.011
Yan, M., B. Li, X. Zhao, G. Ren and Y. Zhuang et al., 2008. Characterization of acid-soluble collagen from the skin of walleye pollock (Theragra chalcogramma). Food Chem., 107: 1581-1586. DOI: 10.1016/j.foodchem.2007.10.027

Yang, S.J., J.H. Hong, S.J. Yang and J.H. Hong, 2012. Extraction and physicochemical properties of collagen from squid (Todarodes pacificus) skin and Alaska pollack (Theragra chalcogramma) skin. Korean J. Food Cookery Sci., 28: 711-719. DOI: $10.9724 / \mathrm{kfcs} .2012 .28 .6 .711$

Zhang, J. and R. Duan, 2017. Characterisation of acidsoluble and pepsin-solubilised collagen from frog (Rana nigromaculata) skin. Int. J. Biol. Macromolecules, 101: 638-642. DOI: $10.1016 /$ j.ijbiomac.2017.03.143

Zhou, P., S.J. Mulvaney and J.M. Regenstein, 2006. Properties of alaska pollock skin gelatin: A comparison with tilapia and pork skin gelatins. J. Food Sci., 71: C313-C321. DOI: $10.1111 /$ j.1750-3841.2006.00065.x

Zhou, P. and J.M. Regenstein, 2004. Optimization of extraction conditions for pollock skin gelatin. J. Food Sci., 69: C393-C398. DOI: $10.1111 / \mathrm{j} .1365-2621.2004 . t b 10704 . x$

Zhou, P. and J.M. Regenstein, 2005. Effects of alkaline and acid pretreatments on Alaska pollock skin gelatin extraction. J. Food Sci., 70: C392-C396. DOI: $10.1111 / \mathrm{j} .1365-2621.2005 . t b 11435 . \mathrm{x}$ 